\title{
EXPERIMENTAL STUDY ON THE EFFECT OF CROSS-SECTIONAL AREA RATIO BETWEEN TUNNEL AND SHAFT ON PLUG-HOLING PHENOMENA IN SHALLOW UNDERGROUND TUNNELS
}

\author{
KUN HYUK SUNG \& HONG SUN RYOU \\ Chung-Ang University, South Korea
}

\begin{abstract}
Urban railways have been widely constructed due to high economic and operational efficiency compared with other traffic systems. In the other hands, urban railways on the grounds cause severe traffic congestion as well as noise and vibrations. In addition, fire accidents in underground tunnels causes many causalities due to suffocation. To solve the drawbacks around world, many researches in various fields have been conducted to utilize underground spaces, e.g., shallow underground tunnels. Natural ventilation systems (NVS) have been widely used for exhausting smoke flows in shallow underground tunnels due to convenience in installation, maintenance and low cost. When the plugholing phenomena occurs in NVS, the actual smoke ventilation rate becomes smaller than the design value due to fresh air inflows below smoke layer. The phenomena correlate relative intensity ratio between horizontal flow and vertical flow immediately below the shaft. Therefore, tunnel geometrics can affect the plug-holing occurrence even fire size is equivalent. In this study, we experimentally investigated the effect of area ratio on the plug-holing phenomena in shallow underground tunnels. The area ratio is defined as the cross-sectional area ratio of shaft to tunnel. To change the area ratio, the only shaft size was changed in the same model tunnel in 1/20 reduced scale. Experiments were carried out for four area ratios (AR) of $0.054,0.071,0.09$ and 0.11 . Also, fire size was fixed to $11.49 \mathrm{~kW}$. As the results, the plug-holing occurred in case of $\mathrm{AR}=0.071,0.09$ and 0.11 . As the area ratio increases, vertical flow through the shaft becomes relatively stronger than the ceiling jet flow in tunnel due to an increase in the exhaust rate of smoke, it causes that the fresh air below the smoke layer can be entrained into the shaft directly. Consequently, the potential for the occurrence of plug-holing increases as the area ratio increases.
\end{abstract}

Keywords: plug-holing, area ratio, ceiling-jet flows, stack effect.

\section{INTRODUCTION}

Urban railways have been widely constructed due to high economic and operational efficiency compared with other traffic systems. In the other hands, urban railways on the grounds cause severe traffic congestion as well as noise and vibrations. In addition, fire accidents in underground tunnels causes many causalities due to suffocation. To solve the drawbacks around world, many researches in various fields have been conducted to utilize underground spaces, e.g., shallow underground tunnels.

In tunnels fires, smoke and hot gas rapidly spread along the ceiling to the whole tunnel immediately after the fire. Also, evacuation routes are the same with the primary way that smoke spreads, which causes many human causalities due to toxic gas suffocation. Therefore, exhausting or controlling smoke is very important in ensuring the evacuation route in the fire cases.

Natural ventilation system (NVS), in which smoke is exhausted by the stack effect of a vertical shaft, have been widely used in shallow underground tunnels due to convenience in installation. The buoyancy force of smoke mainly affects the performance of NVS related to the passive smoke exhaust [1]. Therefore, it is necessary to accurately calculate the maximum smoke discharge capacity of NVS at a tunnel design stage. 
In fire cases, the vertical flow, which is driven by buoyancy force of smoke, is affected by fire size and NVS geometrics, e.g., heat release rate (HRR), cross-sectional area ratio of tunnel/shaft, height of shaft, hydraulic diameter of tunnel, and so on. Meanwhile, the plugholing phenomena is one of the influence factors for the performance of NVS. In practice, the fresh air under smoke layer directly flows into the shaft with the smoke and it is defined as "Plug-holing" [2], thereby the actual amount of smoke exhaust becomes smaller than the design value when the plug-holing occurs in the NVS.

Many researches have been conducted to develop the prediction index for the occurrence of plug-holing in the NVS depending on various influence factors. Hinkley [2] initially introduced the plug-holing phenomenon and suggested the modified Froude number $\left(F r_{H}\right)$, which is defined as the ratio of momentum force and buoyancy force of the smoke, as the criterion on the occurrence of plug-holing. However, the height of shaft, which affects buoyancy force of smoke induced by the stack effect, is not considered in the Hinkley's criterion. Ji et al. [3] carried out the reduced-scale experiments to investigate the effect of shaft height and heat release rate on the plug-holing in NVS and suggested the modified Richardson number $\left(R i_{J}\right)$. Baek et al. [4], however, found that the both existing criterion are incapable to predict the occurrence of plug-holing accurately depending on the hydraulic diameter.

In this study, we experimentally investigated the effect of cross-sectional area ratio of tunnel on the plug-holing in a reduced-scale model tunnel.

\section{THEORETICAL BACKGROUNDS}

\subsection{Plug-holing phenomenon}

In the view of physics, the occurrence of plug-holing is determined by whether the fresh air flows into the shaft, and the phenomena is associated with the ratio of momentum force and buoyant force of the smoke flow under the shaft [5]. Fig. 1 shows the schematic for the occurrence of plug-holing in NVS. In tunnel fires, the fire plume, i.e., smoke, arises and then flows along the ceiling which is called as the ceiling jet flow. The smoke is eventually exhausted through the shaft and the fresh air is entrained into the shaft with the vertical flow with the exhausting smoke. The sunken area is formed by the smoke layer interface between the smoke flow and the fresh air. When the apex of the sunken area is located higher than the height of the tunnel, it is judged that the plug-holing occurs because the pure fresh air directly flows into the shaft. Here, the shape of sunken area is associated with the characteristics of the ceiling jet and the vertical flows. Consequently, the plug-holing phenomenon is significantly affected by the relative flow intensity between the ceiling jet and the shaft, that is, the ratio of horizontal momentum force to buoyancy force acting on the sunken area.

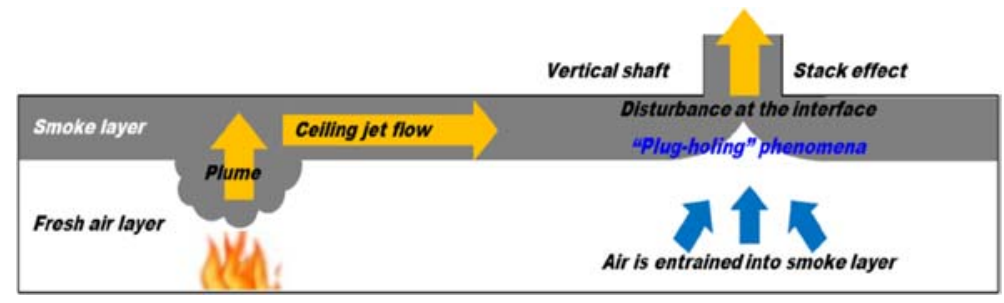

Figure 1: Schematic for the occurrence of plug-holing in the natural ventilation tunnel. (Source: Baek et al. [4].) 


\subsection{Estimation of occurrence of plug-holing}

In this study, it is judged that plug-holing occurred in NVS when the smoke layer interface penetrates inside the shaft as shown in Fig. 2. Therefore, it is essential to define smoke layer interface and estimate temperature distribution in the interface plane. The temperature of smoke layer interface was calculated by using Janssens' model [6] from vertical temperature profile at V-line which is $0.3 \mathrm{~m}$ away from the vertical center of shaft. Consequently, we considered that plug-holing occurred if there is a point in $\mathrm{H}$-line at which the temperature (Tsh) is lower than that of smoke layer interface (Ts), i.e., Tsh $<$ Ts.

\section{EXPERIMENTAL STUDY}

A $1 / 20$ reduced scale shallow tunnel was modelled for numerical study considering NVS. The area ratio (AR) is defined as the cross-sectional area ratio of shaft to tunnel, i.e. $A R=A_{s h} / A_{t u}$. Fig. 3 shows the reduced-scale model tunnel depending on the area ratio. Tunnel width $\left(w_{t u}\right)$ is $7 \mathrm{~m}$ and the vertical ventilation shaft was $2.3 \mathrm{~m}$ apart from the pool fire. To change the area ratio, the only shaft size was changed in the same model tunnel. Tunnel height $\left(h_{t u}\right)$ and tunnel depth $\left(d_{t u}\right)$ were fixed to $0.3 \mathrm{~m}$ and $0.42 \mathrm{~m}$, respectively. In this study, four area ratios, i.e., $0.054,0.071,0.09,0.11$, were considered with the shaft cross-sectional area in experiments Fig. 3.

In Fig. 3, the wall region near fire source was made up of steel plates with a thickness of $0.003 \mathrm{~m}$ (gray color) and the other regions (blue color) were made up of acrylic plates with a thickness of $0.008 \mathrm{~m}$ to observe smoke flows in the model tunnel. Also, n-Heptane pool fire was used as the fire source and mass loss rate was measured with the load cell (AMD CS-004) to calculate heat release rate (HRR). When the fire reached the quasi-steady state, the HRR was estimated to $11.49 \mathrm{~kW}$.

To estimate the smoke layer interface using the Janssens' model, thermocouple trees were installed at two locations, i.e., H-line and V-line as described in Fig. 2. Each thermocouple tree consisted of 6-8 thermocouples (K-type, OMEGA ${ }^{\circledR}$ ) depending on the tunnel or shaft size. Three replications were carried out for each experimental case to improve the accuracy of experimental results. Ambient conditions for pressure and temperature were $1 \mathrm{~atm}$ and $18^{\circ} \mathrm{C}$, respectively.

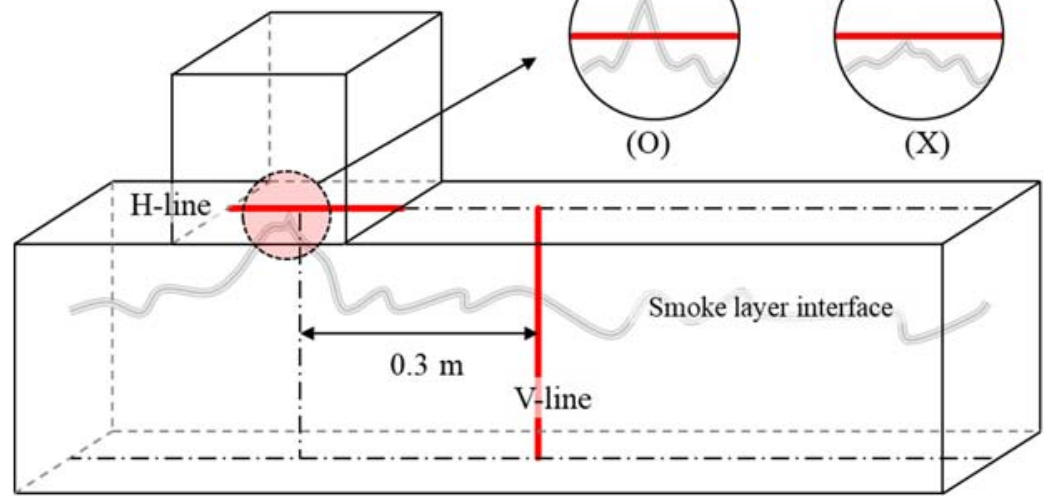

Figure 2: Schematics for judgement of plug-holing. 

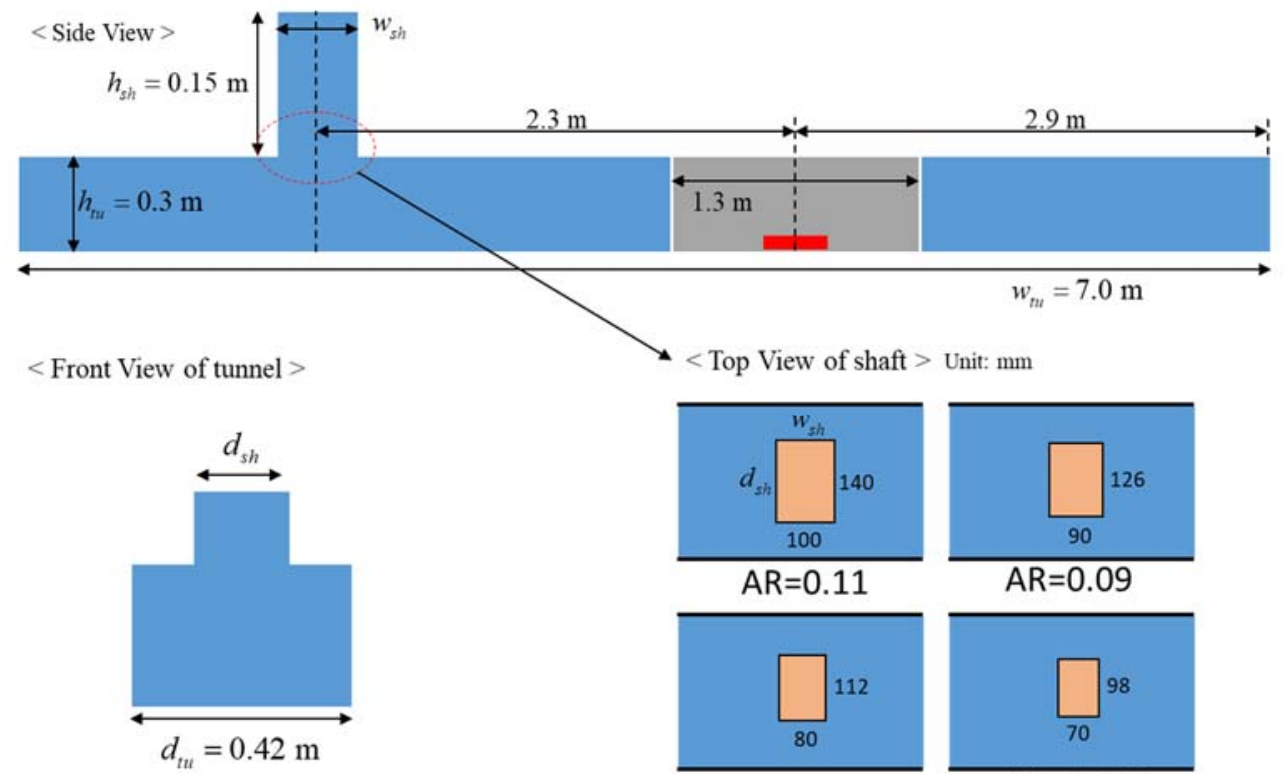

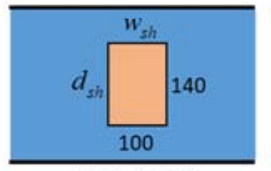

$\mathrm{AR}=0.11$

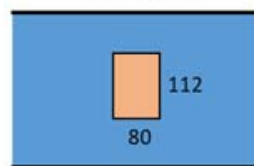

$\mathrm{AR}=0.071$

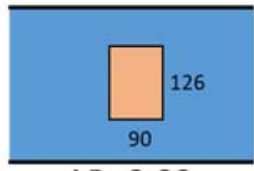

$\mathrm{AR}=0.09$

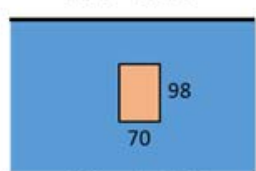

$\mathrm{AR}=0.054$

(a)

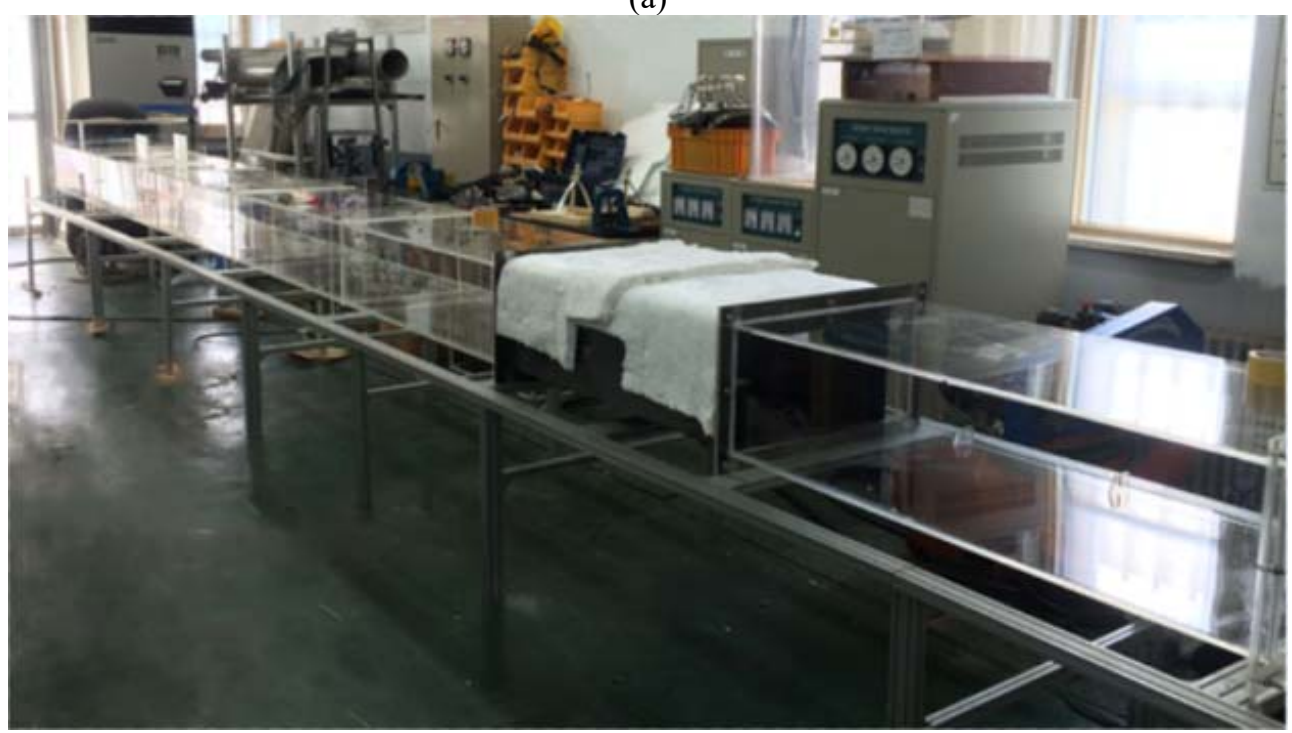

(b)

Figure 3: Reduced-scale model tunnel. (a) Schematics depending on the area ratio; (b) Photograph.

\section{RESULTS AND DISCUSSION}

In this study, plug-holing phenomena was analysed with the mean values, i.e., temperature and velocity, during the quasi-steady state. So, each variable was averaged with the interval 
of $10 \mathrm{~s}$. We considered that thermal fluid flows in the tunnel reached the quasi-steady-state if there is a difference less than $5 \%$ between mean values of the current interval and previous interval.

Fig. 4 shows temperature distribution in V-line depending on the area ratio. Temperature increases as the area ratio increases, i.e., the cross-sectional area of shaft becomes larger. In the NVS, the primary driving force for smoke flows is the stack effect induced by temperature difference between the smoke in the shaft and the ambient air. As the cross-sectional area increases, the discharge flow rate through the shaft also increases, and it leads to an increase in the ceiling jet velocity. As a result, heat loss on wall surfaces increases and the smoke temperature along the ceiling decreases.

Fig. 5 shows the horizontal temperature distribution in $\mathrm{H}$-line depending on the area ratio. In the figure, horizontal positions were normalized with the width of shaft in each case to compare the temperature distribution among all cases and the point where the normalized width is zero is on the direction of fire source.

Overall, smoke temperature decreases as the area ratio increases i.e. the cross-sectional area becomes larger. In addition, the difference of maximum temperature in $\mathrm{H}$-line and $\mathrm{V}$ line increases as presented in Table 1. The results mean that more fresh air is entrained to the shaft as the area ratio increases, and the phenomena is generally related with two causes.

Firstly, as the discharge flow rate through the shaft increases, disturbances on smoke layer interface will be stronger greatly due to the sudden change in flow direction, it leads to more fresh inflows to the shaft. Secondly, when the upstream smoke flow rate, i.e., ceiling jet flow, is less than the discharge flow rate, the fresh air can directly flow to the shaft. In the both cases, therefore, it is likely to occur the plug-holing phenomena.

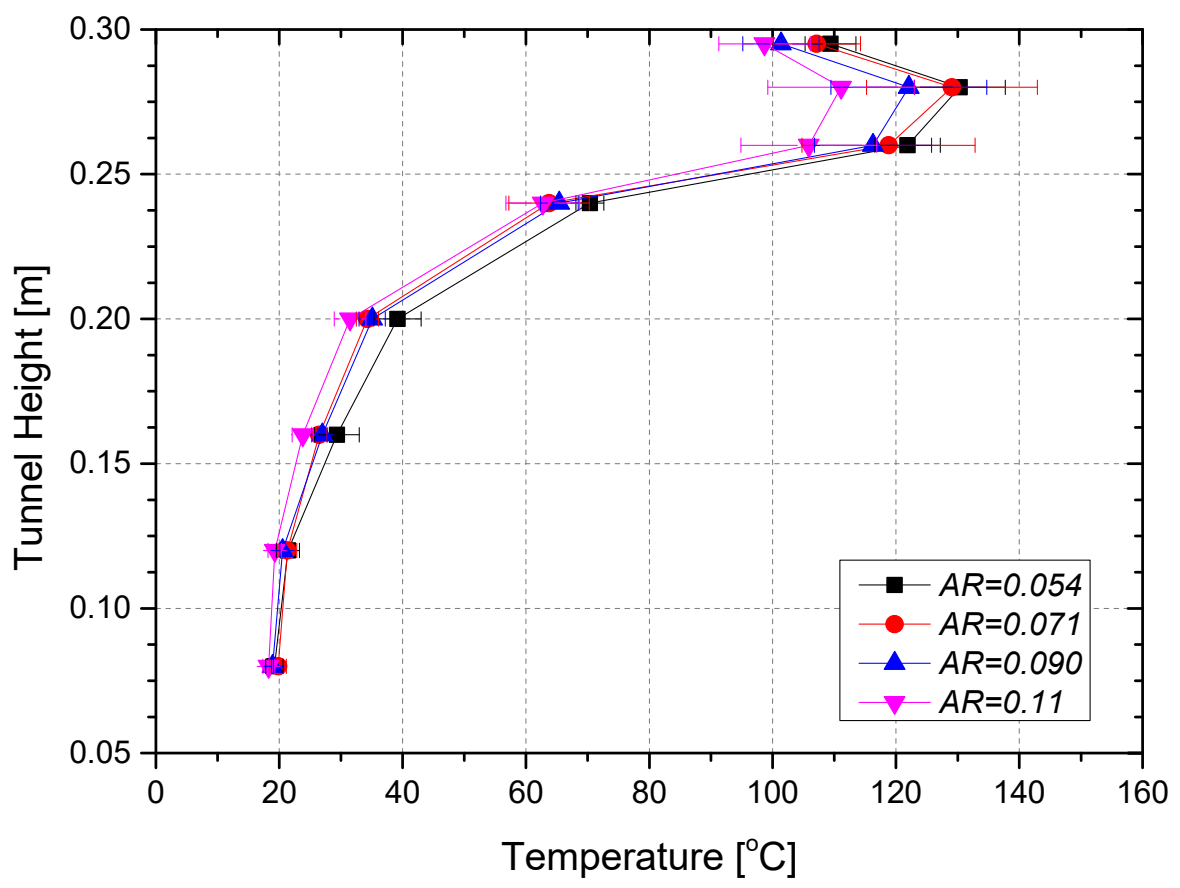

Figure 4: Temperature distribution in V-line depending on the area ratio. 


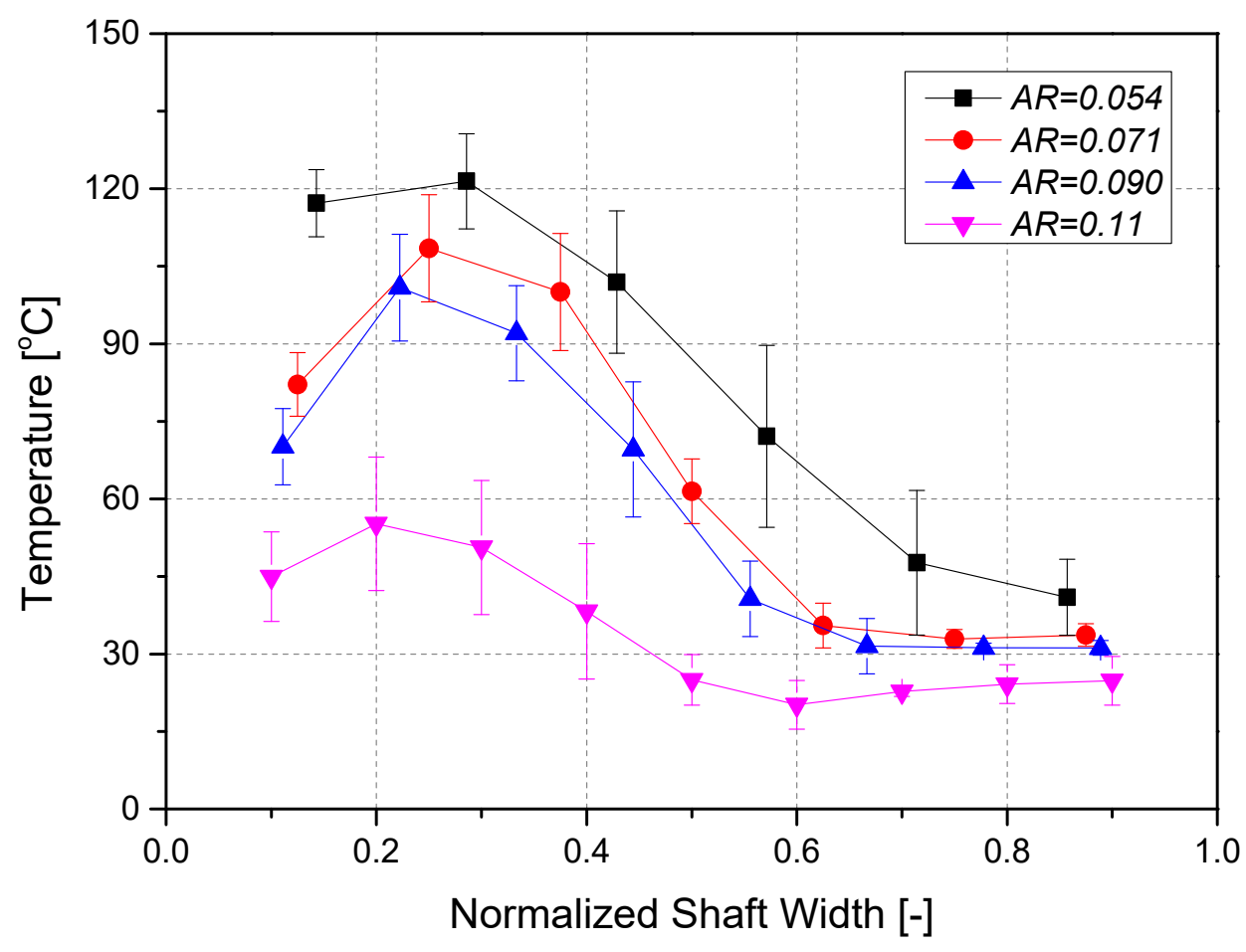

Figure 5: Temperature distribution in H-line depending on the area ratio.

Table 1: The difference of maximum temperature in V-line and $\mathrm{H}$-line depending on the area ratio.

\begin{tabular}{|c|c|c|c|}
\hline $\begin{array}{c}\text { Area Ratio, } \\
A R[-]\end{array}$ & $\begin{array}{c}\text { Max. Temperature } \\
\text { in V-line, }\left[{ }^{\circ} \mathrm{C}\right]\end{array}$ & $\begin{array}{c}\text { Max. Temperature } \\
\text { in H-line, }\left[{ }^{\circ} \mathrm{C}\right]\end{array}$ & $\begin{array}{c}\text { Temperature } \\
\text { difference, }\left[{ }^{\circ} \mathrm{C}\right]\end{array}$ \\
\hline 0.054 & 130.4 & 121.5 & 8.9 \\
\hline 0.071 & 129.1 & 108.5 & 20.6 \\
\hline 0.090 & 122.1 & 100.9 & 21.2 \\
\hline 0.11 & 111.1 & 55.2 & 55.9 \\
\hline
\end{tabular}

To judge whether the plug-holing phenomena occurred or not, the minimum temperature $\left(T_{s h}\right)$ in H-line was compared with the temperature of smoke layer interface $\left(T_{s}\right)$ calculated from V-line. Plug-holing occurs when $T_{s h}>T_{s}$. Smoke temperature and judgement of plugholing depending on the area ratio are presented in Table 2.

As the results, plug-holing does not occur in the only area ratio case of 0.054 . It means that the area ratio is one of the influence factors on the plug-holing phenomena. In addition, difference between $T_{s h}$ and $T_{s}$ becomes larger as the area ratio increases, and the tendency is consistent with that of the difference of maximum temperature presented at Table 1 . In the other words, as the area ratio increases, more fresh air is entrained into the shaft, and consequently, the potential for occurrence of plug-holing increases. 
Table 2: Smoke temperature and plug-holing occurrence depending on the area ratio.

\begin{tabular}{|c|c|c|c|c|}
\hline $\begin{array}{c}\text { Area } \\
\text { Ratio, } \\
A R[-]\end{array}$ & $\begin{array}{c}\text { Smoke layer } \\
\text { interface } \\
\text { height, } \\
h_{s}[\mathrm{~m}]\end{array}$ & $\begin{array}{c}\text { Minimum } \\
\text { temperature in } \mathrm{H}- \\
\text { line, } T_{s h}\left[{ }^{\circ} \mathrm{C}\right]\end{array}$ & $\begin{array}{c}\text { Temperature of } \\
\text { Smoke layer } \\
\text { interface, } T_{s} \\
{\left[{ }^{\circ} \mathrm{C}\right]}\end{array}$ & $\begin{array}{c}\text { Plug-holing } \\
\text { Occurrence }\end{array}$ \\
\hline 0.054 & 0.18 & 29.1 & 35.8 & $\mathrm{X}$ \\
\hline 0.071 & 0.20 & 32.8 & 31.4 & $\mathrm{O}$ \\
\hline 0.090 & 0.20 & 32.7 & 28.3 & $\mathrm{O}$ \\
\hline 0.11 & 0.21 & 33.5 & 26.1 & $\mathrm{O}$ \\
\hline
\end{tabular}

\section{CONCLUSIONS}

In this study, we experimentally the effect of the area ratio on the plug-holing phenomena with a constant heat release rate of $11.49 \mathrm{~kW}$.

- As the area ratio increases, overall temperature in tunnel and shaft decreases because heat loss through wall increases with the discharge flow rate through the shaft.

- As the area ratio increases, the difference of maximum temperature in $\mathrm{H}$-line and $\mathrm{V}$-line increases due to more fresh air inflows to the shaft.

- As the area ratio increases, the potential for occurrence of plug-holing increases.

Consequently, as the area ratio increases, vertical flow through the shaft becomes relatively stronger than the ceiling jet flow in tunnel due to an increase in the discharge rate through the shaft. As a result, the fresh air below the smoke layer can be entrained into the shaft directly. In addition, parameter study for heat release rate is essential to develop the prediction index for plug-holing phenomena as the further study.

\section{ACKNOWLEDGEMENTS}

This research was supported by Fire Fighting Safety \& 119 Rescue Technology Research and Development Program funded by the Ministry of Public Safety and Security ("MPSSFire Fighting-2015-80”).

\section{REFERENCES}

[1] Heskestad, G., Smoke distributions from fire plumes in uniform downdraft from a ceiling. Fire Safety Journal, 39(5), pp. 358-374, 2004.

[2] Hinkley, P., The flow of hot gases along an enclosed shopping mall a tentative theory. Fire Safety Science, 807, 1970.

[3] Ji, J. et al., A study of the effect of plug-holing and boundary layer separation on natural ventilation with vertical shaft in urban road tunnel fires. International Journal of Heat and Mass Transfer, 55(21-22), pp. 6032-6041, 2012.

[4] Baek, D., Bae, S. \& Ryou, H.S., A numerical study on the effect of the hydraulic diameter of tunnels on the plug-holing phenomena in shallow underground tunnels. Journal of Mechanical Science and Technology, 31(5), pp. 2331-2338, 2017.

[5] Baek, D., Sung, K.H. \& Ryou, H.S., Experimental study on the effect of heat release rate and aspect ratio of tunnel on the plug-holing phenomena in shallow underground tunnels. International Journal of Heat and Mass Transfer, 113, pp. 1135-1141, 2017.

[6] Janssens, M. \& Tran, H.C., Data reduction of room tests for zone model validation. Journal of Fire Sciences, 10(6), pp. 528-555, 1992. 